ARTICLE

\title{
Boride-derived oxygen-evolution catalysts
}

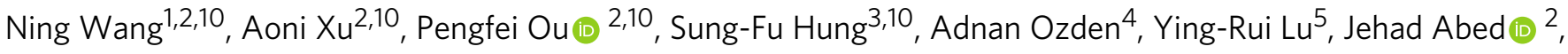 \\ Ziyun Wang $\mathbb{0}^{2}$, Yu Yan², Meng-Jia Sun², Yujian Xia ${ }^{6}$, Mei Han¹, Jingrui Han¹, Kaili Yao ${ }^{1}$, Feng-Yi Wu ${ }^{3}$, \\ Pei-Hsuan Chen ${ }^{3}$, Alberto Vomiero (1) 7,8, Ali Seifitokaldani ${ }^{9}$, Xuhui Sun (10 6, David Sinton (10 ${ }^{3}$, \\ Yongchang Liu (i) ${ }^{1 凶}$, Edward H. Sargent (iD ${ }^{2 \otimes}$ \& Hongyan Liang ${ }^{1 凶}$
}

Metal borides/borates have been considered promising as oxygen evolution reaction catalysts; however, to date, there is a dearth of evidence of long-term stability at practical current densities. Here we report a phase composition modulation approach to fabricate effective borides/borates-based catalysts. We find that metal borides in-situ formed metal borates are responsible for their high activity. This knowledge prompts us to synthesize NiFe-Boride, and to use it as a templating precursor to form an active NiFe-Borate catalyst. This boride-derived oxide catalyzes oxygen evolution with an overpotential of $167 \mathrm{mV}$ at $10 \mathrm{~mA} / \mathrm{cm}^{2}$ in $1 \mathrm{M} \mathrm{KOH}$ electrolyte and requires a record-low overpotential of $460 \mathrm{mV}$ to maintain water splitting performance for over $400 \mathrm{~h}$ at current density of $1 \mathrm{~A} / \mathrm{cm}^{2}$. We couple the catalyst with $\mathrm{CO}$ reduction in an alkaline membrane electrode assembly electrolyser, reporting stable $\mathrm{C}_{2} \mathrm{H}_{4}$ electrosynthesis at current density $200 \mathrm{~mA} / \mathrm{cm}^{2}$ for over $80 \mathrm{~h}$.

\footnotetext{
${ }^{1}$ School of Materials Science and Engineering, Tianjin University, Tianjin 300350, China. ${ }^{2}$ Department of Electrical and Computer Engineering, University of Toronto, 35 St George Street, Toronto, Ontario M5S 1A4, Canada. ${ }^{3}$ Department of Applied Chemistry, National Chiao Tung University, Hsinchu 300 Taiwan, ROC. ${ }^{4}$ Department of Mechanical and Industrial Engineering, University of Toronto, 5 King's College Road, Toronto, Ontario M5S 3G8, Canada. ${ }^{5}$ National Synchrotron Radiation Research Center, Hsinchu 30076 Taiwan, ROC. ${ }^{6}$ Institute of Functional Nano \& Soft Materials (FUNSOM), Jiangsu Key Laboratory for Carbon-Based Materials and Devices, Soochow University, Suzhou, Jiangsu 215123, China. ${ }^{7}$ Division of Materials Science, Department of Engineering Sciences and Mathematics, Luleå University of Technology, 97187 Luleå, Sweden. ${ }^{8}$ Department of Molecular Sciences and Nanosystems, Ca' Foscari University of Venice, Via Torino 155, 30172 Venezia Mestre, Italy. ${ }^{9}$ Department of Chemical Engineering, McGill University, Montreal, Quebec H3A OC5,

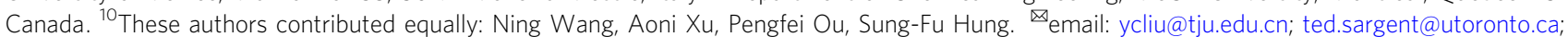
hongyan.liang@tju.edu.cn
} 
T he design of active, stable, and cost-effective catalysts for the oxygen evolution reaction (OER) is critical to improving the full process efficiency in electrocatalytic systems, such as water splitting and $\mathrm{CO}_{2} / \mathrm{CO}$ reduction reaction $\left(\mathrm{CO}_{2} / \mathrm{CORR}\right)$ coupled with $\mathrm{OER}^{1-4}$. In these systems, approaches that use alkaline electrolytes have the benefit of increasing efficiency toward $\mathrm{CO}_{2} \mathrm{RR}$ and CORR by suppressing the competing hydrogen evolution reaction (HER).

While there have been improvements in the activity of metal phosphides, sulfides, selenides, and borides/borates ${ }^{5-8}$, achieving high electrocatalytic activity $\left(>1 \mathrm{~A} / \mathrm{cm}^{2}\right)$ united with long-term stability $(>100 \mathrm{~h})$ remains an unmet need ${ }^{9,10}$. The lack of highly active and stable OER catalysts limits the performance and stability of electrosynthesis processes that rely on an OER anode (i.e., $\mathrm{CO}_{2} \mathrm{RR} / \mathrm{CORR}$ electrolysers) to production rates $<100 \mathrm{~mA} /$ $\mathrm{cm}^{2}$ and durations of $<100 \mathrm{~h}$. It remains an important task for the field to increase catalytic activity while achieving long-term durable and earth-abundant OER catalysts that operate at alkaline $\mathrm{pH}$.

Metal borides/borates exhibit promising OER performance in high-pH regimes: incorporating highly electronegative boron diminishes the metal oxidation reaction energy barrier under a positive bias and assists with charge transfer ${ }^{11,12}$. To date, the durability of metal borides has been limited to $<60 \mathrm{~h}$ at a modest current density of $\sim 20 \mathrm{~mA} / \mathrm{cm}^{2,13-15}$. Thus far, to improve the activity and stability, significant efforts have been invested in charge-transfer enhancement and electronic structure optimization; however, we found herein that metal borides are prone to convert into metal borate under OER conditions, and thus to behave as the operando catalyst ${ }^{16-18}$.

This knowledge prompted us to design metal borides as precursors to construct, in-situ, the metal borates that would endow the catalysts with activity and stability.

We focused on a NiFe-Boride compound and probed its phase transformation using operando X-ray spectroscopy during OER. We witnessed the in-situ transformation of NiFeBoride to $\mathrm{NiB}_{4} \mathrm{O}_{7}$ and $\mathrm{FeBO}_{3}$ phases on the catalyst surface during electrochemical activation. These results accord with DFT calculations which reveal that $\mathrm{NiB}_{4} \mathrm{O}_{7}$ species facilitate the step ${ }^{*} \mathrm{O}->{ }^{*} \mathrm{OOH}$ and enhance electrocatalytic activity toward OER.

Experimentally, we achieve an overpotential of $167 \mathrm{mV}$ at $10 \mathrm{~mA} / \mathrm{cm}^{2}$ and stable water splitting performance of $400 \mathrm{~h}$ at $1 \mathrm{~A} / \mathrm{cm}^{2}$. Encouraged by its high activity and stability, we implement NiFe-Boride as the OER catalyst in a CORR membrane-electrode assembly (MEA) electrolyser that uses $\mathrm{CO}$ and $\mathrm{H}_{2} \mathrm{O}$ to produce $\mathrm{C}_{2} \mathrm{H}_{4}{ }^{19}$. The CORR electrolyser based on the NiFe-Boride OER catalyst exhibited stable performance at $200 \mathrm{~mA} / \mathrm{cm}^{2}$ for over $80 \mathrm{~h}-$ maintaining a $\mathrm{C}_{2} \mathrm{H}_{4}$ energy efficiency of $19 \%$ - whereas this value is $17 \%$ for the CORR electrolyser that relies on a noble $\mathrm{IrO}_{2}$ OER catalyst.

\section{Results}

Insight from computational studies into stable and active phases. Noting that metal borides undergo phase transformation at highly oxidative potentials, we sought to calculate Pourbaix diagrams to evaluate the phase composition of NiFe-Boride ternary system at high potentials in alkaline electrolytes. Compared to the Pourbaix diagram of NiFe (Fig. 1a), we observe two new stable phases, $\mathrm{FeBO}_{3}$ and $\mathrm{NiB}_{4} \mathrm{O}_{7}$, under a working potential $(U=1.4-2 \mathrm{~V}$ vs. RHE) at electrolyte $\mathrm{pH}(\mathrm{pH}=10-14)$ of alkaline OER in the Pourbaix diagram of NiFe-Boride (Fig. 1b), indicating that boron ions promote the new phases formation. The atomic configurations of these two new phases are shown in the Fig. 1c.
We carried out density functional theory (DFT) calculations to further explore the effects of these in-situ formed phases on the OER activity of NiFe catalyst. We first calculated the reaction energy of elementary steps and the overpotential for the OER based on the 4e-mechanism proposed by Nørskov et al. for water oxidation $^{20-22}$ with the reaction pathway:

$$
\begin{gathered}
*+\mathrm{OH}^{-} \rightarrow{ }^{*} \mathrm{OH}+e^{-} \\
* \mathrm{OH}+\mathrm{OH}^{-} \rightarrow{ }^{*} \mathrm{O}+\mathrm{H}_{2} \mathrm{O}+e^{-} \\
* \mathrm{O}+\mathrm{OH}^{-} \rightarrow{ }^{*} \mathrm{OOH}+\mathrm{e}^{-} \\
* \mathrm{OOH}+\mathrm{OH}^{-} \rightarrow \mathrm{O}_{2}+\mathrm{H}_{2} \mathrm{O}+\mathrm{e}^{-}
\end{gathered}
$$

We cleaved the (100) facet of these two new phases to study the adsorption energy of various intermediates for OER, and thus to determine the theoretical overpotentials as an indicator for catalytic activity (Fig. 1d and Supplementary Fig. 1). The largest reaction energy (Step 2, deprotonation of $* \mathrm{OH}$ ) was identified as the potential-determining step (PDS) ${ }^{23}$, as shown in Fig. 1e, and the reaction energy was similar for both $\mathrm{FeBO}_{3}(0.53 \mathrm{~V})$ and $\mathrm{NiOOH}(0.56 \mathrm{~V})$ at $1.23 \mathrm{~V}$. In contrast, $\mathrm{NiB}_{4} \mathrm{O}_{7}$ shows a thermodynamic overpotential of $0.43 \mathrm{~V}$, lowest among $\mathrm{NiOOH}$, $\mathrm{NiFeOOH}$ and $\mathrm{FeBO}_{3}$, which suggests that $\mathrm{NiB}_{4} \mathrm{O}_{7}$ phases are the active sites in NiFe-Boride that enable superior catalytic OER performance. We observed that the $\mathrm{NiB}_{4} \mathrm{O}_{7}$ shifts the PDS to the ${ }^{*} \mathrm{OOH}$ formation step at $1.23 \mathrm{~V}$. We also obtained the similar calculation results at $1.40 \mathrm{~V}$ (Fig. 1e and Supplementary Fig. 2).

To account for other possible reaction mechanisms, we further studied the intramolecular oxygen coupling mechanism ${ }^{24}$ : we found that $\mathrm{Ni}$ and $\mathrm{Fe}$ borate have increased activity compared to $\mathrm{Ni}$ and $\mathrm{Fe}$ (oxy)hydroxide (Supplementary Fig. 3). We also considered more sophisticated activity descriptors for multipleelectron processes, exploring the use of electrochemical-step symmetry index (ESSI) and the PDS at zero overpotential $\left(\mathrm{G}_{\max }\right)^{25-27}$ : these results indicated higher OER activities of these NiFe-borate phases (Supplementary Table 1). Taken together, these results indicate that boron addition enables formation of new active phases, especially the $\mathrm{Ni}$ phase, in the pristine framework, thereby enhancing electrocatalytic activity toward OER.

Catalyst synthesis and characterization. To test these hypotheses experimentally, we synthesized NiFe-Boride catalysts by a chemical reduction method (see Methods for details). Transmission electron microscopy (TEM), scanning electron microscopy (SEM), and X-ray diffraction (XRD) were conducted to investigate the structure, composition, and morphology of the NiFeBoride catalyst. TEM and SEM images (Supplementary Figs. 4 and 5) revealed that catalysts the consisted of agglomerated nanoparticles. Elemental mapping analysis indicated that $\mathrm{Ni}, \mathrm{Fe}$, $\mathrm{B}$, and $\mathrm{O}$ elements distribute homogeneously, without obvious separation or aggregation (Fig. 2a and Supplementary Fig. 6). A broad XRD diffraction peak between $40^{\circ}$ and $50^{\circ}$ indicates low crystallinity in the catalyst (Fig. 2b).

We further carried out X-ray photoelectron spectroscopy (XPS) to study the chemical state of the NiFe-Boride catalyst. XPS survey spectra show the presence of $\mathrm{Ni}, \mathrm{Fe}, \mathrm{B}$, and $\mathrm{O}$, which agrees well with the elemental mapping results (Supplementary Fig. 7). The B $1 s$ spectrum obtained from the pristine sample was comprised of two peaks located at $192 \mathrm{eV}$ and $187 \mathrm{eV}$, which are assigned to $\mathrm{B}-\mathrm{O}$ and $\mathrm{B} / \mathrm{B}-\mathrm{M}$ species (Fig. 2c), respectively, indicating boride. The $\mathrm{Ni}$ and $\mathrm{Fe} K$-edge $\mathrm{X}$-ray absorption nearedge structure (XANES, Fig. 2d, e) revealed that NiFe-Boride possesses an electronic structure that differs from that of the control samples, indicating that the incorporation of boride leads 

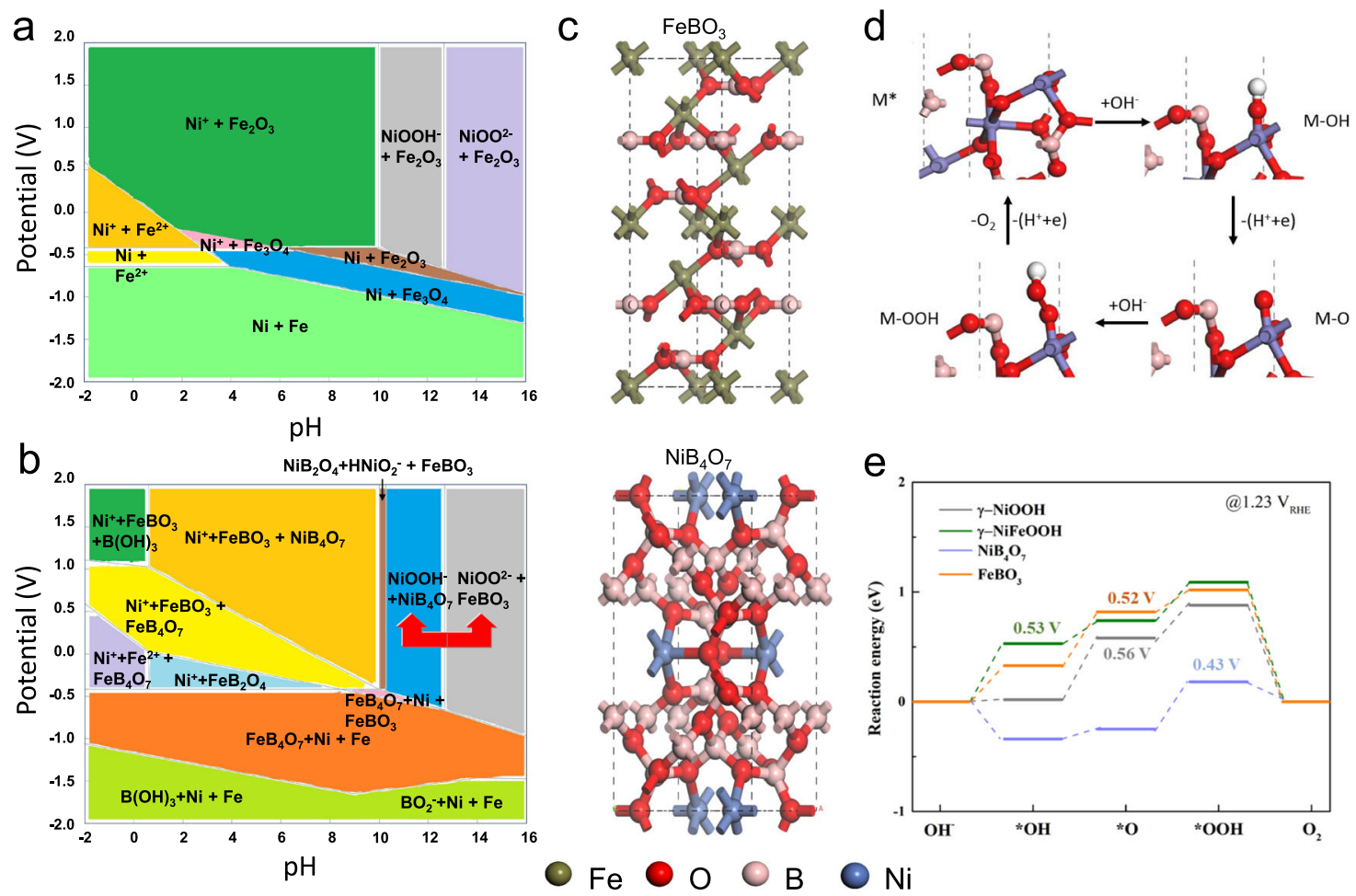

Fig. 1 Results of DFT calculations for NiFe-Boride catalysts. Pourbaix diagram of (a) NiFe and (b) NiFe-Boride; (c) The cell configurations of $\mathrm{NiB}_{4} \mathrm{O}_{7}$ and $\mathrm{FeBO}_{3} ;$ (d) The schematic illustration of the 4-step OER pathway; (e) Predicted OER reaction energy diagram for $\mathrm{NiB}_{4} \mathrm{O}_{7}, \mathrm{FeBO}_{3}, \gamma-\mathrm{NiOOH}$, and $\gamma$ $\mathrm{NiFeOOH}$ in the alkaline electrolyte at $1.23 \mathrm{~V}$ vs. RHE.

to phase and structural changes. To probe the origins of these changes, we obtained a Fourier transform (FT) of the extended X-ray absorption fine structure (EXAFS, Fig. 2f, g) spectrum. NiFe-Boride showed two FT features: (1) the peak at $\sim 1.5 \AA$ represents the single-scattering path of $\mathrm{M}-\mathrm{O}$ and (2) the peak at $\sim 2.5 \AA$ results from the single-scattering path of the closest neighboring transition metals around the metal cations (M-M) (the locations of the peaks match the locations of those in the $\mathrm{NiFe}$ control sample) ${ }^{28}$. The altered electronic structure suggests that the boride ions were incorporated into the NiFe framework via the formation of $\mathrm{BO}_{x}$ and $\mathrm{NiFeB}_{x}$ species. Further investigations of the $\mathrm{M}-\mathrm{B}$ peak remain a topic of interest.

Using inductively coupled plasma optical emission spectrometry (ICP-OES) analysis, we determined the molar ratio of $\mathrm{Ni}$ :Fe to be 1:1. Further analysis of the as-deposited system with the aid of energy-dispersive X-ray spectroscopy (EDS) indicated a 1:1 atomic ratio of Ni:Fe (Supplementary Fig. 8).

In-situ and ex-situ characterization. Using in-situ synchrotron radiation X-ray diffraction (SRXRD), we tracked changes in the crystal structure of catalysts during the OER process. We found that, prior to OER, the phase structure of the catalyst was $\mathrm{NiFeBO}_{4}$ (see Supplementary Fig. 9 for the model structure). We found that $\mathrm{FeBO}_{3}$ and $\mathrm{NiB}_{4} \mathrm{O}_{7}$ were formed under an applied potential (Fig. 3a, the standard patterns are provided in the Supplementary Fig. 10), consistent with in-situ formation of new phases in the NiFe-Boride catalyst during OER. We then carried out in-situ XAS to monitor the local electronic structure changes of the metal sites during the OER. The $\mathrm{Ni}$ and Fe $K$-edge XANES (Fig. 3b, c) spectra exhibited a positive energy shift, i.e., the valence states of $\mathrm{Ni}$ and $\mathrm{Fe}$ increased with the applied potential ${ }^{29}$. We analyzed the absorption edge energies in order to characterize the $\mathrm{Ni} / \mathrm{Fe}$ valence states. Before OER, the valence states of $\mathrm{Ni}$ and $\mathrm{Fe}$ in NiFe-Boride were 1.91 and 2.73, respectively. During OER, the valence states of $\mathrm{Ni}$ and $\mathrm{Fe}$ increased to 1.98 and 2.95, respectively (Supplementary Figs. 11-13). The ex-situ L-edge XAS results were in good agreement with this change: the reacted catalyst - compared to the pristine one - had a higher $\mathrm{Ni}^{3+}$ ratio and a similar $\mathrm{Fe}^{2+/ 3+}$ ratio. The similarity in $\mathrm{Fe}^{2+/ 3+}$ ratios indicates that Fe ions return to their initial states upon release of the applied potential. These results accord with the higher $\mathrm{Ni}^{3+}$ ratio in the reacted catalyst observed via O K-edge XAS (Supplementary Fig. 14).

We further analyzed the EXAFS spectra (Fig. 3d, e) to clarify the local structural variations associated with the $\mathrm{Ni}$ and $\mathrm{Fe}$ sites $^{30,31}$. Under open circuit potential (OCP) in $\mathrm{KOH}$ electrolyte, the FT peaks demonstrated features similar to those obtained from the as-prepared catalysts. Once a positive bias was applied, the progressive FT peaks show that the original phase accomplishes some structural transformations. We conducted EXAFS fitting (Supplementary Tables 2-3 and Supplementary Figs. 15, 16) to determine the bond lengths of $\mathrm{M}-\mathrm{O}$ and $\mathrm{M}-\mathrm{M}(\mathrm{M}$ is $\mathrm{Ni}$ or $\mathrm{Fe})$. The interatomic distances of $\mathrm{Ni}-\mathrm{O}$ and $\mathrm{Ni}-\mathrm{Ni}(\mathrm{Fe})$ in as-prepared NiFe-Boride are $2.04 \AA$ and $3.09 \AA$, respectively, while those measured during OER are $2.02 \AA$ and $2.98 \AA$. The interatomic distances of $\mathrm{Fe}-\mathrm{O}$ and $\mathrm{Fe}-\mathrm{Fe}(\mathrm{Ni})$ in as-prepared $\mathrm{NiFe}$ Boride are $2.23 \AA$ and $3.22 \AA$, while those measured during OER are 1.92 and $3.05 \AA$. As oxidation and phase transformation progress, the $\mathrm{M}-\mathrm{O}$ and $\mathrm{M}-\mathrm{M}$ bonds become shorter than those at OCP. These results are in line with the generation of transition metal active sites with high valence ${ }^{29}$. The electronic structure of $\mathrm{NiFe}$-Boride is different than that of Ni-Boride and Fe-Boride, indicating the presence of electronic communication between the $\mathrm{Ni}$ and $\mathrm{Fe}$ in $\mathrm{M}-\mathrm{M}$ bonds (Supplementary Fig. 17).

We carried out XPS to study the local evolution of chemical state and electronic structure before vs. after OER, with all peaks calibrated using C $1 s$ (Supplementary Fig. 18). High-resolution $\mathrm{XPS}$ in $\mathrm{Ni} 2 p$ region showed two main peaks of $\mathrm{Ni}^{2+} 2 p_{3 / 2}$ and $\mathrm{Ni}^{2+} 2 p_{1 / 2}$ located at 855.4 and $873.3 \mathrm{eV}$ (Fig. 3f), accompanied by satellite peaks centered at 861.2 and $879.4 \mathrm{eV}^{32}$. In the Fe $2 p$ 
a

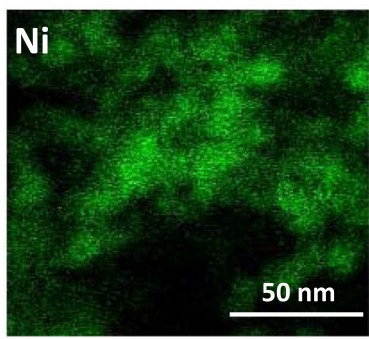

b

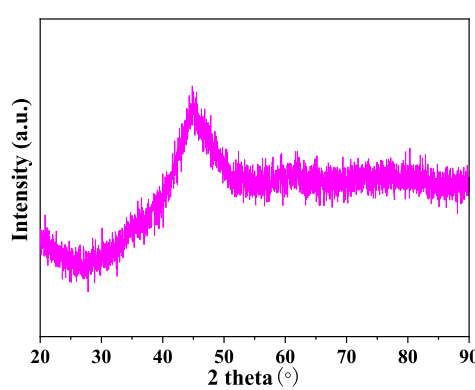

C

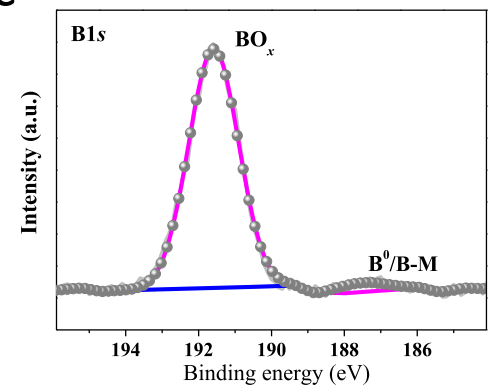

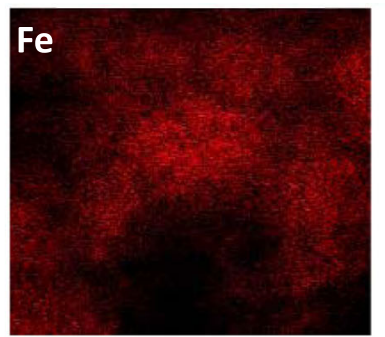


d

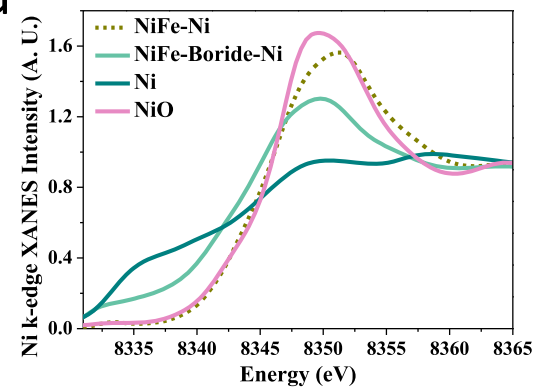

$f$

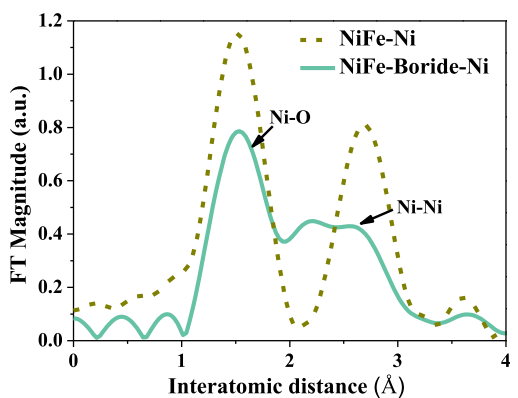

e

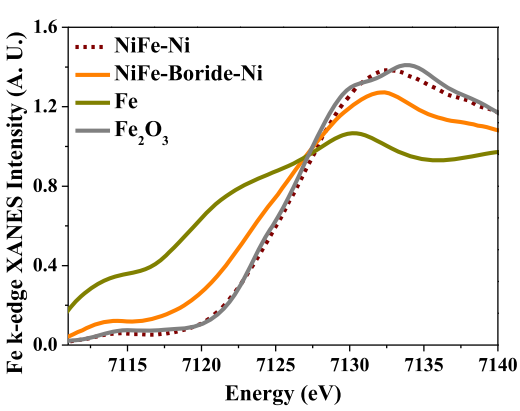

g

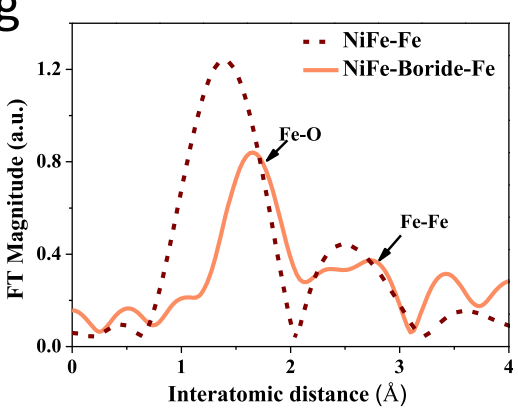

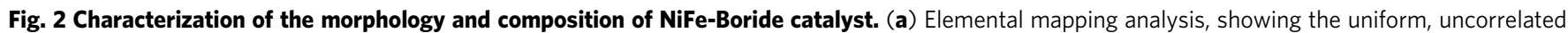
spatial distribution of Ni, Fe, B and O. (b) XRD patterns. (c) B 1 s XPS spectrum of fresh NiFe-Boride sample. The Ni and Fe K-edge XANES (d) and (e) and EXAFS (f) and (g) data for fresh NiFe-Boride and control samples.

region, two main peaks located at 710.7 and $724.6 \mathrm{eV}$ were assigned to $\mathrm{Fe} 2 p_{3 / 2}$ and $\mathrm{Fe} 2 p_{1 / 2}$ (Fig. $3 \mathrm{~g}$ ). We noted minor peaks centered at $\sim 851.9$ and $706.1 \mathrm{eV}$ in the $\mathrm{Ni} 2 p$ and $\mathrm{Fe} 2 p$ spectra of fresh catalyst, suggesting the existence of $\mathrm{Ni}-\mathrm{B}$ and $\mathrm{Fe}-\mathrm{B}$ bonds in $\mathrm{NiFe}$-Boride (Fig. 3f, g) ${ }^{33}$, consistent with EXAFS. The B $1 s$ spectrum consists of two peaks corresponding to $\mathrm{B}-\mathrm{O}$ and $\mathrm{B}^{0} / \mathrm{B}$ $\mathrm{M}$ species. Upon completion of electrochemical activation during OER, negative chemical shifts in the binding energy of $\mathrm{Ni} 2 p$ and Fe $2 p$ peaks were observed compared to pristine NiFe-Boride. These negative shifts indicated the modulation of the surface electronic structure through the oxidation process, in accordance with the positive shift in the peak position of B-O bonds (Supplementary Fig. 19). Harsh oxidative conditions during OER converted the $\mathrm{M}-\mathrm{B}$ species into oxides and hydroxides, evidenced by the disappearance of $\mathrm{Ni}-\mathrm{B}, \mathrm{Fe}-\mathrm{B}$, and $\mathrm{B}^{0} / \mathrm{B}-\mathrm{M}$ signals.

In sum, $\mathrm{NiFe}$-Boride acts as a precursor that phase transforms at highly oxidative potentials, leading to the formation of stable $\mathrm{FeBO}_{3}$ and $\mathrm{NiB}_{4} \mathrm{O}_{7}$ phases during the OER process.

Electrocatalytic performance. The OER performance of $\mathrm{NiFe}$ Boride and controls on $\mathrm{Ni}$ foam was examined in $1 \mathrm{M} \mathrm{KOH}$ electrolyte using a three-electrode cell at room temperature (see Methods). As shown in linear sweep voltammetry (LSV, Fig. 4a) curves, the overpotential of NiFe-Boride catalyst at $10 \mathrm{~mA} / \mathrm{cm}^{2,34}$ and without $i R$ compensation is $167 \mathrm{mV}$. This is lower than the $200 \mathrm{mV}$ and $189 \mathrm{mV}$ obtained for sol-gel NiFe and $\mathrm{IrO}_{2}$, respectively (Supplementary Table 4). Rotating ring disk measurements show a similar trend: NiFe-Boride enables higher-rate water oxidation performance than in control catalysts (Supplementary Fig. 20). To seek insight into the effect of in-situ active sites on performance, we compared the catalytic activity between annealed and pristine catalysts. The annealed catalysts have lower performance, consistent with an activity-promoter role for the in-situ formed active sites (Supplementary Figs. 21-22). A Ni:Fe ratio of 1:1 (Supplementary Fig. 23 and Table 5) leads to the lowest overpotential. We determined the Tafel slope (Fig. 4b), finding $25 \mathrm{mV} / \mathrm{dec}$ for the $\mathrm{NiFe}$-Boride catalyst, lower than for $\mathrm{IrO}_{2}$ $(41 \mathrm{mV} / \mathrm{dec})$ and $\mathrm{NiFe}(66 \mathrm{mV} / \mathrm{dec})$. The lower Tafel slope value indicating rate-determining step is shifted from the ${ }^{*} \mathrm{O}$ step to the *OOH formation step ${ }^{35,36}$. Compared to benchmark OER catalysts from literature, $\mathrm{NiFe}$-Boride shows higher catalytic performance in terms of overpotential at $10 \mathrm{~mA} / \mathrm{cm}^{2}$ and Tafel slope in the alkaline solution (Fig. 4c). From Nyquist plots based on electrochemical impedance spectroscopy (EIS, Fig. 4d) at applied potential $1.45 \mathrm{~V}$ vs. RHE reveal that $\mathrm{NiFe}$-Boride exhibits a lower charge-transfer resistance $\left(\mathrm{R}_{c t}\right)$ than does either $\mathrm{NiFe}$ or $\mathrm{IrO}_{2}$.

We then used electrochemically active surface area (ECSA) obtained via the double-layer capacitance $\left(C_{d l}\right.$, Supplementary Fig. 24) technique to estimate a normalized current density 37 This for NiFe-Boride is $7.5 \mathrm{~mA} / \mathrm{cm}^{2},>2 \mathrm{x}$ greater than that in $\mathrm{IrO}_{2}$, and $4 \mathrm{x}$ greater than in NiFe catalysts, at $1.45 \mathrm{~V}$ vs. RHE (Supplementary Fig. 25). IR-corrected LSV excludes the effect of ionic conductivity on performance: the NiFe-Boride catalyst showed an $i R$-corrected overpotential of $160 \mathrm{mV}$ at $10 \mathrm{~mA} / \mathrm{cm}^{2}$ 

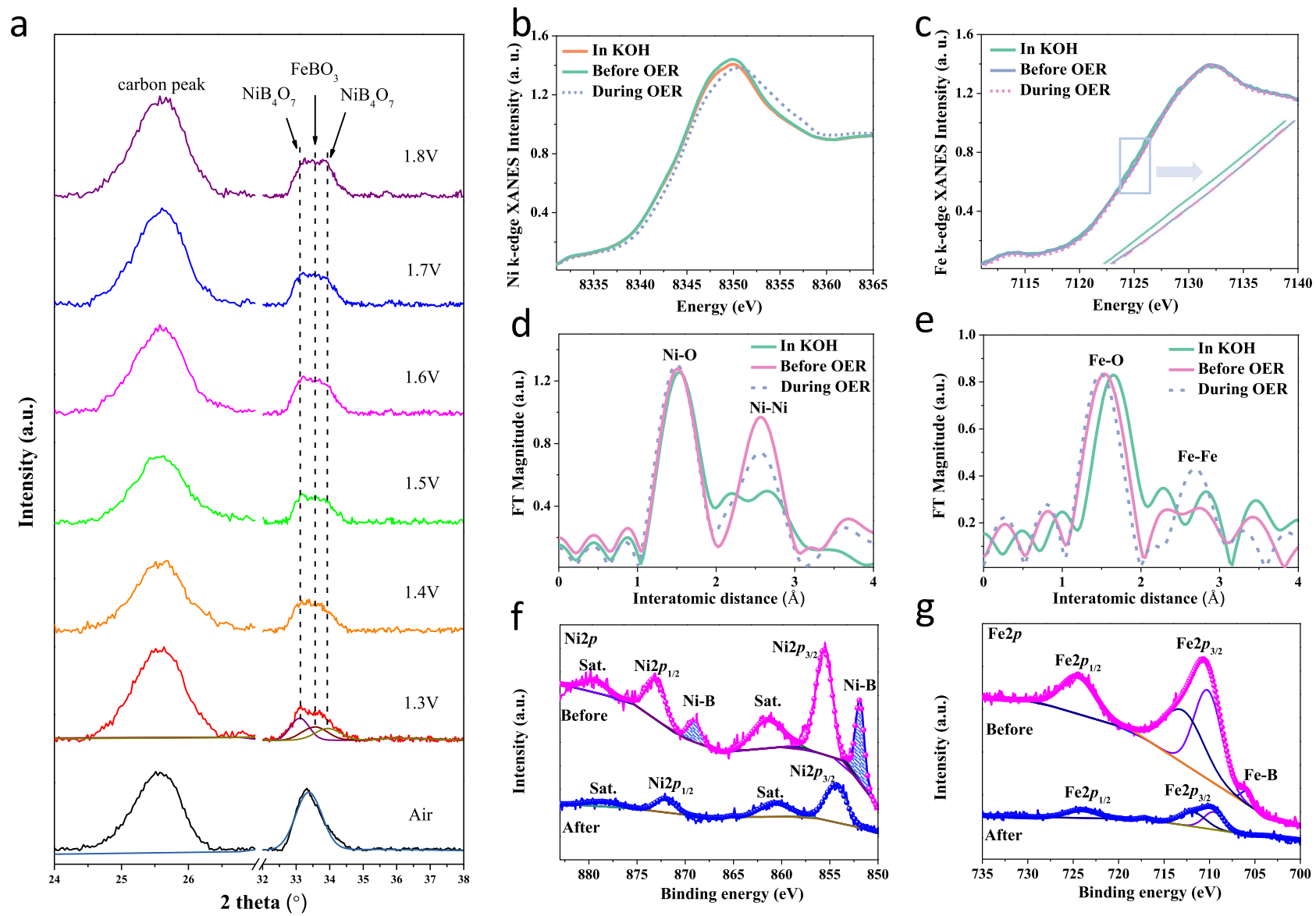

Fig. 3 Ex/in-situ characterization of as-prepared NiFe-Boride catalyst. a In-situ SRXRD patterns of the catalyst during the OER test in $1 \mathrm{M} \mathrm{KOH}$ electrolyte; The in-situ Ni and Fe K-edge XANES (b) and (c) and EXAFS (d) and (e) data of NiFe-Boride during the LSV process in $1 \mathrm{M} \mathrm{KOH}$ aqueous electrolyte. The in-situ applied voltages before and during the OER are 1.2 and $1.4 \mathrm{~V}$ vs. RHE, respectively. f Ni $2 p$ and (g) Fe $2 p$ XPS spectra for fresh and post-OER samples.

on $\mathrm{Ni}$ foam (Supplementary Fig. 26), which is 35 and $23 \mathrm{mV}$ lower than for NiFe and $\mathrm{IrO}_{2}$.

We measured the stability of the best-performing NiFe-Boride catalyst at $20 \mathrm{~mA} / \mathrm{cm}^{2}$ and found that the increase in potential was less than $10 \mathrm{mV}$ after $100 \mathrm{~h}$ of continuous water splitting (Fig. 4e), more stable than the control and reference samples (Fig. 4f). We obtained stability at $1 \mathrm{~A} / \mathrm{cm}^{2}$, finding that catalysts enable stable operation of $400 \mathrm{~h}$ with an overpotential of $460 \mathrm{mV}$ without degradation (Fig. 4g). B $1 \mathrm{~s}$ XPS results indicate that the B concentration gradually decreases over the first $100 \mathrm{~h}$ but then remains constant over the ensuing $300 \mathrm{~h}$ (Supplementary Fig. 27). The Faradaic efficiency (FE) toward $\mathrm{O}_{2}$ remains $98 \pm 2 \%$ over the first $400 \mathrm{~h}$, excluding a major current contribution associated with materials corrosion.

To investigate further the potential relevance of these catalysts to future systems, we implemented NiFe-Boride as the OER catalyst in a CORR MEA electrolyser that produces $\mathrm{C}_{2} \mathrm{H}_{4}$ from $\mathrm{CO}$ and $\mathrm{H}_{2} \mathrm{O}$ (Supplementary Fig. 28). The CORR electrolyser exhibited stable performance at $200 \mathrm{~mA} / \mathrm{cm}^{2}$ for over $80 \mathrm{~h}$, maintaining a cell potential of $-2.85 \mathrm{~V}, \mathrm{a} \mathrm{C}_{2} \mathrm{H}_{4} \mathrm{FE}$ of $45 \%$, and a $\mathrm{C}_{2} \mathrm{H}_{4}$ energy efficiency of $19 \%$. Under similar operating conditions, the cell potential for the $\mathrm{IrO}_{2}$ OER catalyst-based electrolyser was $-3.06 \mathrm{~V}$, which is $\sim 200 \mathrm{mV}$ higher than in the NiFe-Boride OER catalyst-based system (Fig. 4h and Supplementary Fig. 29), corresponding to a $\mathrm{C}_{2} \mathrm{H}_{4}$ energy efficiency of $17 \%$. Using XPS and EDS line scanning, we found that $\mathrm{Ni}, \mathrm{Fe}$, and $\mathrm{B}$ elemental signals remained following the stability study (Supplementary Figs. 30 and 31)., i.e., the borate remained in the NiFe.

\section{Discussion}

Starting from DFT calculations, we saw that the phase transformation of NiFe-Boride to NiFe-Borate can be activated under OER potentials in OER. The in-situ formed new phase $\left(\mathrm{NiB}_{4} \mathrm{O}_{7}\right)$ can function as active site to facilitate $* \mathrm{O}->* \mathrm{OOH}$, enhancing the electrocatalytic activity of NiFe-Boride in OER. We evaluated the electrochemical performance of the catalyst and found that NiFe-Boride possesses a Tafel slope of $25 \mathrm{mV} / \mathrm{dec}$ and an overpotential of $167 \mathrm{mV}$ at current density $10 \mathrm{~mA} / \mathrm{cm}^{2}$ in $1 \mathrm{M} \mathrm{KOH}$ solution, outperforming benchmark NiFe oxide. The in-situ formed NiFe-Borate phases are confirmed via operando spectroscopies. The catalyst demonstrates stable performance over $400 \mathrm{~h}$ at $1 \mathrm{~A} / \mathrm{cm}^{2}$ in water splitting. We further showcased $80 \mathrm{~h}$ of stable $\mathrm{C}_{2} \mathrm{H}_{4}$ electrosynthesis using a NiFe-Boride OER catalyst in a CORR MEA electrolyser, with a $\sim 200 \mathrm{mV}$ lower cell potential compared to MEA electrolysers based $\mathrm{IrO}_{2}$ OER catalysts.

\section{Methods}

I.1. Chemicals. Iron (III) chloride $\left(\mathrm{FeCl}_{3}\right)$, nickel (II) chloride hexahygrate $\left(\mathrm{NiCl}_{2} \cdot 6 \mathrm{H}_{2} \mathrm{O}\right)$, Sodium borohydride $\left(\mathrm{NaBH}_{4}\right)$, ethanol $(\geq 99.5 \%)$ and acetone ( $\geq 99 \%$ ) were purchased from Sigma-Aldrich. Iridium (IV) oxide dehydrate (99.99\%) was purchased from Alfa Aesar ${ }^{\oplus}$. All chemicals were used without further purification.

I.2. Synthesis of NiFe-Boride and control catalysts. Th NiFe-Boride catalysts were synthesized using a modified chemical reduction method. $\mathrm{NiCl}_{2} \cdot 6 \mathrm{H}_{2} \mathrm{O}$ $(332.8 \mathrm{mg})$ and anhydrous $\mathrm{FeCl}_{3}(227.1 \mathrm{mg})$ were first dissolved in deionized water (DI, $2 \mathrm{~mL})$ in a vial. A solution of $\mathrm{NaBH}_{4}(2 \mathrm{~mL}, 5 \mathrm{M})$ in water was prepared in a separate vial. All solutions mentioned above were cooled in an ice bath for $10 \mathrm{~min}$ 
a

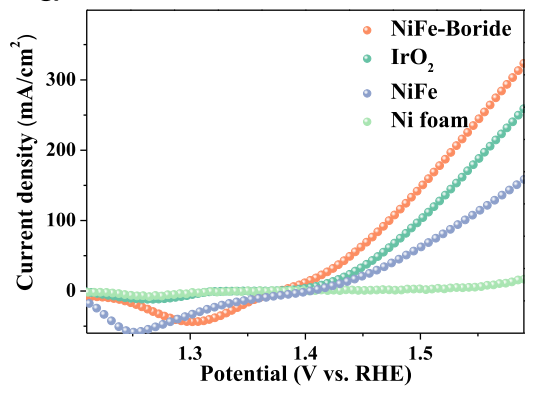

d

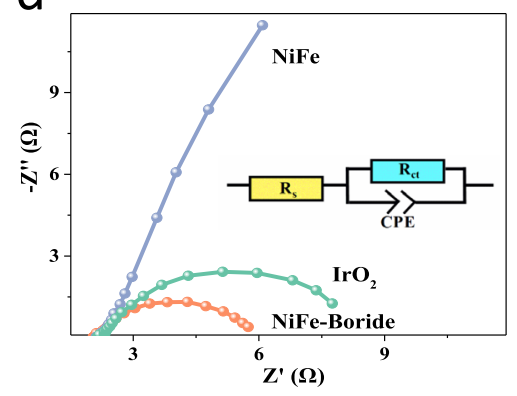

b
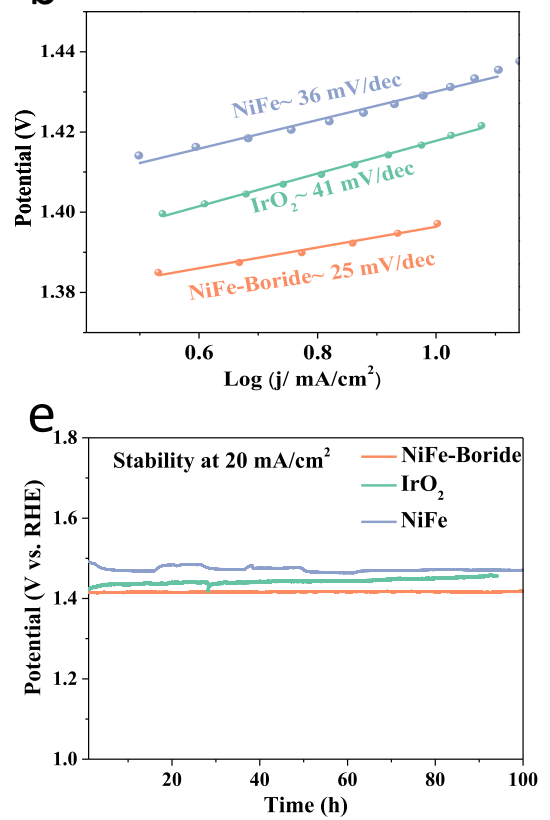

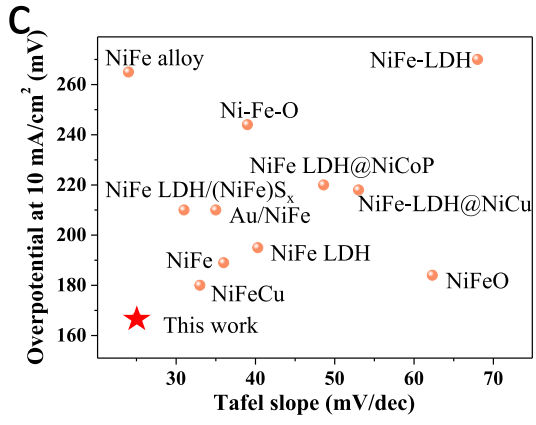

$f$

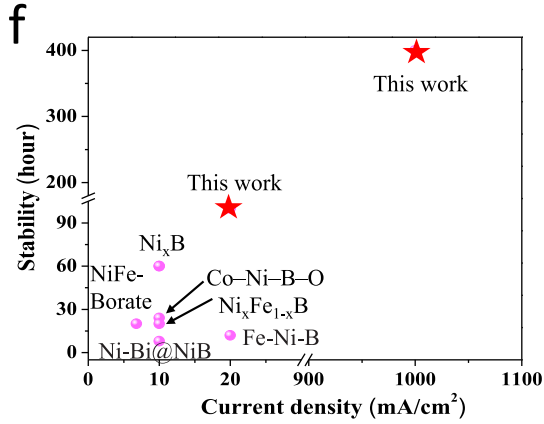

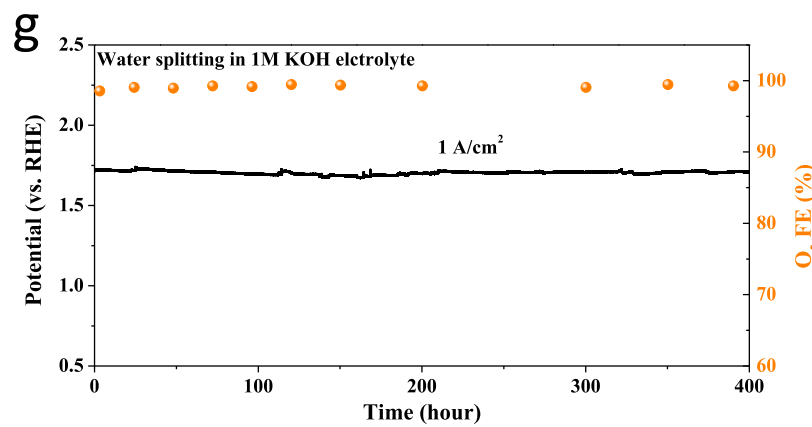

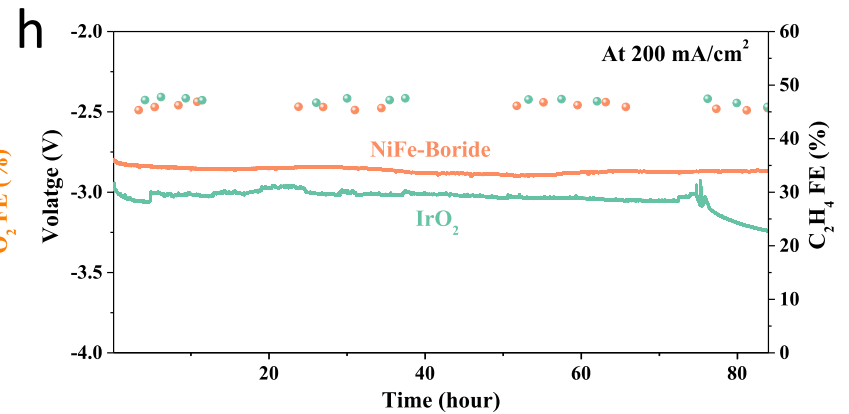

Fig. 4 Performance of NiFe-Boride catalyst and controls in a three-electrode configuration in $\mathbf{1 M}$ KOH aqueous electrolyte. a OER LSV polarization curves for catalysts loaded on Ni foam without $i R$ correction. b The corresponding Tafel plot of catalysts. c Comparison of Tafel slope and overpotential required to achieve $10 \mathrm{~mA} / \mathrm{cm}^{2}$, with references all measured in alkaline medium ${ }^{47-57}$. d EIS data for NiFe-Boride and controls in three-electrode configuration. The data were collected at $1.45 \mathrm{~V}$ vs. RHE. The inset provides the equivalent circuit: $R_{s}$ series resistance, $R_{c t}$ charge-transfer resistance, and CPE constant-phase element related to the double-layer capacitance. e Chronopotentiometric curves obtained from the NiFe-Boride catalyst on Ni foam electrode at a constant current density of $20 \mathrm{~mA} / \mathrm{cm}^{2}$. $\mathbf{f}$ Comparison of stability at different current density, with references all measured in alkaline medium ${ }^{13-15,33,58}$. g Operating voltage and $\mathrm{O}_{2} \mathrm{FE}$ at constant $1 \mathrm{~A} / \mathrm{cm}^{2}$ current density in a three-electrode configuration in $1 \mathrm{M} \mathrm{KOH}$ aqueous electrolyte. h The operating voltage and ethylene $\mathrm{FE}$ were monitored at constant $200 \mathrm{~mA} / \mathrm{cm}^{2}$ in a membrane-electrode assembly device. NiFe-Boride and $\mathrm{rrO}_{2}$ supported on titanium felt were used as the anodes. The high surface area $\mathrm{Cu}$ catalyst on hydrophobic carbon paper acted as cathode. Humidified $\mathrm{CO}$ was flowed through the gas channels in the cathode, and $2 \mathrm{M}$ aqueous $\mathrm{KOH}$ solution was flowed through channels in the anode.

to prevent uncontrolled hydrolysis and consideration which may lead to the formation of the precipitate. The $\mathrm{Ni}$ and Fe precursors were then added dropwise to $\mathrm{NaBH}_{4}$ to form a black solution. Finally, the prepared solution was further washed and centrifuged with water and ethanol three times before vacuum drying. The samples of different $\mathrm{Ni}: \mathrm{Fe}$ ratios were synthesized by changing the $\mathrm{Ni}$ and $\mathrm{Fe}$ precursors concentration.

NiFe catalysts were synthesized using a modified aqueous sol-gel technique. $\mathrm{NiCl}_{2} \cdot 6 \mathrm{H}_{2} \mathrm{O}(2.1 \mathrm{mmol})$ and anhydrous $\mathrm{FeCl}_{3}(0.35 \mathrm{mmol})$ were first dissolved in ethanol $(2 \mathrm{~mL})$ in a vial. A solution of deionized water (DI) $(0.18 \mathrm{~mL})$ in ethanol $(2 \mathrm{~mL})$ was prepared in a separate vial. All solutions mentioned above were cooled in an ice bath for $2 \mathrm{~h}$ to prevent uncontrolled hydrolysis and consideration, which may lead to the formation of precipitate rather than gel formation. The $\mathrm{Ni}$ and $\mathrm{Fe}$ precursors were then mixed with an ethanol-water mixture to form a clear solution. Propylene oxide $(\approx 1 \mathrm{~mL})$ was then slowly added to form a gel. Finally, the prepared NiFe wet-gel was aged for $24 \mathrm{~h}$ to promote network formation and immersed in acetone for 5 days before the gel was vacuum dried.

I.3. Characterization. The morphologies of the catalysts were characterized by SEM (Hitachi S-4800) imaging, and energy-dispersive X-ray spectroscopy mapping operated at $1.5 \mathrm{kV}$ was used to characterize the surfaces of all samples. TEM images and corresponding elemental mapping analysis were conducted using a JEM-
2100F. The electronic structure measurements were carried out using XPS (ESCALAB 250Xi). To determine the best $\mathrm{Ni} / \mathrm{Fe}$ ratio in the NiFe-Boride system, we first dissolved $50 \mathrm{mg}$ of the catalyst into $5 \mathrm{ml}$ aqua regia through microwave digestion. Then, we took out $1 \mathrm{ml}$ of sample and diluted it to $10 \mathrm{~mL}$ to test ICPOES (5110).

In-situ XAS was carried out in the same condition as electrocatalytic characterization case using a modified single cell with an opening sealed by Kapton tape. The XAS signal was collected by Vortex detector in 9BM beamline of Advanced Photon Source (APS) in Argonne National Laboratory. X-ray absorption near-edge spectra (XANES) of $\mathrm{Ni}$ and $\mathrm{Fe} K$-edge were collected by silicon drift detector at ambient air in 9BM beamline of Advanced Photon Source (APS) located in the Argonne National Laboratory.

In-situ SRXRD measurements on NiFe-Boride in a typical three-electrode setup as the same condition in electrochemical characterization case were conducted at beamline $01 \mathrm{C} 2$ at National Synchrotron Radiation Research Center using a specially designed acrylic container with a $1 \mathrm{~mL}$ of gap, sealed by Kepton tape $16 \mathrm{keV}$ of the incident $\mathrm{X}$-ray $(\lambda=0.7749 \AA)$ was allowed to perpendicularly transmit through the sample and electrolyte, so that the signal of synchrotron X-ray diffraction of transmission mode would be collected in a large DebyeScherrer camera and processed using the GSAS-II software 45 to obtain plots of intensity versus $2 \theta$. 
1.4. Catalysts loaded on the electrodes. To load the catalyst on the Ni foam (thickness: $1.6 \mathrm{~mm}$, Sigma), $20 \mathrm{mg}$ of catalyst was dispersed in a mixture consisting of $2 \mathrm{~mL}$ water and $2 \mathrm{~mL}$ ethanol, followed by the addition of $100 \mu \mathrm{L}$ Nafion solution. The suspension was sonicated for $30 \mathrm{~min}$ to prepare a homogeneous ink. $\mathrm{Ni}$ foam with a fixed area of $0.5 \times 0.5 \mathrm{~cm}^{2}$ coated with water-resistant silicone glue was drop-casted with $20 \mu \mathrm{L}$ of the catalyst ink. $\mathrm{Ag} / \mathrm{AgCl}$ (with saturated $\mathrm{KCl}$ as the filling solution) and platinum foil were used as the reference and counter electrodes, respectively.

I.5. Electrochemical characterization. Electrochemical measurements were performed using a three-electrode system connected to an electrochemical workstation (Autolab PGSTAT302N), equipped with built-in EIS analyzer. The working electrode was Ni foam (thickness: $1.6 \mathrm{~mm}$, Sigma), which was prepared by dispersing $20 \mathrm{mg}$ of catalyst in a mixture containing $1 \mathrm{~mL}$ water and $1 \mathrm{~mL}$ ethanol, followed by the addition of $100 \mu \mathrm{L}$ Nafion solution. The suspension was sonicated for $30 \mathrm{~min}$ to prepare a homogeneous ink. Cyclic voltammetry (CV) measurements at $50 \mathrm{mV} / \mathrm{s}$ were performed prior to recording LSV at $1 \mathrm{mV} / \mathrm{s}$ for each sample. EIS measurements were conducted in a static solution at $1.45 \mathrm{~V}$ (vs. RHE). The amplitude of the sinusoidal wave was $10 \mathrm{mV}$, and the frequency scan range was between $100 \mathrm{kHz}$ and $0.01 \mathrm{~Hz}$. All experiments were performed at ambient temperature $\left(23 \pm 2{ }^{\circ} \mathrm{C}\right)$, and electrode potential was converted to the RHE scale using Eq. (5)

$$
E(v s . R H E)=E(v s . A g / A g C l)+E_{A g / A g C l}(v s . N H E)+0.059 \times p H
$$

MEA test. The MEA cell is a complete CO electrolyser (Dioxide Materials) consisted of a titanium anode flow field, $904 \mathrm{~L}$ Stainless Steel cathode flow field, and associated nuts, bolts and insulating kit. The geometric area of each flow field is $5 \mathrm{~cm}^{2}$, of which $45 \%$ is the channel while the rest $55 \%$ is the land area. The catalyst electrode was attached on the cathode by a copper tape, which was protected by insulating Kapton tapes to avoid electrical contact with membranes or electrolytes. A Sustainion AEM membrane (Fumasep) was activated in $1 \mathrm{M}$ aqueous $\mathrm{KOH}$ solution for $24 \mathrm{~h}$, washed with water prior to use. The anode consisted of NiFeBoride supported on titanium felt was prepared by a dip-coating and thermal decomposition method. The cathode is the high surface area $\mathrm{Cu}$ catalyst on hydrophobic carbon paper. Aqueous $2 \mathrm{M} \mathrm{KOH}$ electrolyte was used as the anolyte and was circulated using a peristaltic pump. The flow rate of the anolyte was kept at $20 \mathrm{~mL} / \mathrm{min}$. The flow rate of the CO gas flowing into the cathodic gas chamber was kept at $80 \mathrm{sccm}$ by a mass flow controller. The CORR was initiated by applying a constant current density of $200 \mathrm{~mA} / \mathrm{cm}^{2}$, and the current density was kept constant over the course of electrolysis.

IR correction. All the polarization curves on different supports were corrected for ohmic losses (including the wiring, substrate, catalyst, and solution resistances). The $i R$-corrected data were given by the following equation:

$$
E_{\text {Corrected }}=E-i R
$$

where $R$ is the series resistance of measurement, which can be obtained from an EIS Nyquist plot as the first intercept of the main arc with the axis.

ECSA. The ECSA of each catalyst was determined by measuring the electrochemical double-layer capacitances $\left(C_{d l}\right)$ from the scan rate CV-dependence plot. The CV cycle potential window was between 0.7 and $0.8 \mathrm{~V}$ vs. RHE, and the scan rates were $20,40,60,80,100$, and $120 \mathrm{mV} / \mathrm{s}$. The $C_{d l}$ was estimated $\Delta j=$ $\frac{1}{2}\left(j_{\text {charge }}-J_{\text {off charge }}\right)$ at the average potential in the selected range against the scan rates. The slope of the linear fit was calculated as the $C_{d l}$. A specific capacitance of $40 \mu \mathrm{F} / \mathrm{cm}^{2}$ was used here. The ECSA of the catalyst was calculated by using the following equation,

$$
E C S A=\frac{C_{d l}}{40 \mu F / \mathrm{cm}^{2}} \mathrm{~cm}_{E C S A}^{2}
$$

DFT calculations. We performed the DFT calculations using the Vienna Ab Initio Simulation Package (VASP) code ${ }^{38,39}$. The exchange-correlation energy was modelled using Perdew-Burke-Ernzerhof (PBE) functional ${ }^{40}$ within the generalized gradient approximation (GGA). The projector augmented-wave (PAW) pseudopotentials ${ }^{41}$ were used to describe the ionic cores. The cut-off energy of $450 \mathrm{eV}$ was adopted after a series of tests. A Methfessel-Paxton smearing of $0.05 \mathrm{eV}$ to the orbital occupation was applied for the geometry optimization and total energy computations. In all calculations, atoms at all positions were assumed to possess Hellmann-Feynman forces lower than $0.02 \mathrm{eV} / \AA$, and the electronic iteration convergence criterion was $10^{-5} \mathrm{eV}$ using the normal algorithm. Pourbaix diagrams were calculated using Atomic Simulation Environment (ASE) ${ }^{42}$ with input formation energy values from Materials project ${ }^{43}$. Surface models for $\mathrm{NiB}_{4} \mathrm{O}_{7}$ and $\mathrm{FeBO}_{3}$ were simulated by five-layer $(2 \times 2) \mathrm{NiB}_{4} \mathrm{O}_{7}(100)$ and $\mathrm{FeBO}_{3}(100)$ supercells (Supplementary Fig. 32), accompanied with a sufficient vacuum gap of $15 \AA$ Å. Structural optimizations were performed on all modified slab models. We considered 4 -steps intermediates adsorption to simulate the OER process (details in below \& Supplementary Fig. 33). During adsorption calculations, the top two layers were fully relaxed, while the other layers were fixed at the tested lattice position.

The reaction energies $(\Delta G)$ were obtained by

$$
\Delta \mathrm{G}=\Delta \mathrm{E}^{\mathrm{DFT}}+\Delta \mathrm{ZPE}-\mathrm{T} \Delta \mathrm{S}
$$

where $\Delta \mathrm{E}^{\mathrm{DFT}}$ is the reaction energy calculated from DFT; $\triangle \mathrm{ZPE}$ is the zero-poin energy, which was neglected here; $\Delta S$ is the change in entropy, and for gaseous molecules $\Delta S$ values are obtained from the standard database in the NIST webbook $^{44}$.

Taking the reaction (1) as an example, the reaction energy is equals to

$$
\Delta \mathrm{G}^{1}=\mathrm{G}\left({ }^{*} \mathrm{OH}\right)-\mathrm{G}\left({ }^{*}\right)-\mathrm{G}\left(\mathrm{OH}^{-}\right)
$$

where $\mathrm{G}\left({ }^{*} \mathrm{OH}\right)$ is the total energy of ${ }^{*} \mathrm{OH}$ adsorption configuration; $\mathrm{G}\left({ }^{*}\right)$ is the energy of catalyst surface; $\mathrm{G}\left(\mathrm{OH}^{-}\right)$is the energy of hydroxyl ion, to calculate this value, we assume the equilibrium

$$
\mathrm{H}_{2} \mathrm{O} \leftrightarrow \mathrm{H}^{+}+\mathrm{OH}^{-}
$$

which relates the chemical potentials as

Then,

$$
\mu_{\mathrm{H}^{+}}+\mu_{\mathrm{OH}^{-}}=\mu_{\mathrm{H}_{2} \mathrm{O}}
$$

Thus,

$$
\mu_{H^{+}}+\mu_{e^{-}}+\mu_{\mathrm{OH}^{-}}-\mu_{e^{-}}=\mu_{\mathrm{H}_{2} \mathrm{O}}
$$

$$
\mu_{\mathrm{OH}^{-}}-\mu_{e^{-}}=\mu_{\mathrm{H}_{2} \mathrm{O}}-\left(\mu_{\mathrm{H}^{+}}+\mu_{e^{-}}\right)
$$

here, $\mu_{H^{+}}+\mu_{e^{-}}$can be calculated using computational hydrogen electrode (CHE) model developed by Nørskov and co-workers ${ }^{45,46}$. Then, the theoretical overpotential $\eta$ for OER can be calculated by

$$
\eta=\max \left(\Delta G^{i}\right)-1.23
$$

$\Delta G^{i}$ stands for the reaction energy for reaction (8) - (11), $i=1,2,3,4$.

Electrochemical-step symmetry index (ESSI) and maximum energy $\mathrm{G}_{\max }$ can act as a sophisticated activity descriptors for multiple-electron processes. We calculated ESSI using the following formula,

$$
E S S I=\frac{1}{n} \sum_{k=1}^{n}\left(\frac{\triangle G_{k}^{+}}{e}\right)
$$

where $\Delta G_{k}^{+}$means all positive values of reaction energies, while negative values are not accounted.

The $\mathrm{G}_{\max }$ is the free-energy spanning from intermediate with the smallest free energy to the intermediate with the highest energy during OER.

\section{Data availability}

The data supporting this study are available within the paper and the Supplementary Information. The source data of DFT calculations are provided in this paper. All other relevant source data are available from the corresponding authors upon reasonable request. Source data are provided with this paper.

Received: 27 January 2021; Accepted: 30 September 2021; Published online: 19 October 2021

\section{References}

1. Yu, Y., Shi, Y. \& Zhang, B. Synergetic transformation of solid inorganic-organic hybrids into advanced nanomaterials for catalytic water splitting. Acc. Chem. Res. 51, 1711-1721 (2018).

2. You, B. \& Sun, Y. Innovative strategies for electrocatalytic water splitting. Acc. Chem. Res. 51, 1571-1580 (2018)

3. Yang, M. Q., Wang, J., Wu, H. \& Ho, G. W. Noble metal-free nanocatalysts with vacancies for electrochemical water splitting. Small 14, el703323 (2018).

4. Wang, Y. \& Yan, D. El Hankari, S., Zou, Y. \& Wang, S. Recent progress on layered double hydroxides and their derivatives for electrocatalytic water splitting. Adv. Sci. 5, 1800064 (2018).

5. Li, H. et al. Earth-abundant iron diboride (FeB2) nanoparticles as highly active bifunctional electrocatalysts for overall water splitting. Adv. Energy Mater. 7, 1700513 (2017).

6. Yu, F. et al. High-performance bifunctional porous non-noble metal phosphide catalyst for overall water splitting. Nat. Commun. 9, 2551 (2018).

7. Panda, C. et al. From a molecular $2 \mathrm{Fe}-2 \mathrm{Se}$ precursor to a highly efficient Iron diselenide electrocatalyst for overall water splitting. Angew. Chem. Int. Ed. 56, 10506-10510 (2017)

8. Yang, Y. et al. MoS2-Ni3S2 heteronanorods as efficient and stable bifunctional electrocatalysts for overall water splitting. ACS Catal. 7, 2357-2366 (2017).

9. Shiva Kumar, S. \& Himabindu, V. Hydrogen production by PEM water electrolysis - A review. Mater. Sci. Energy Technol. 2, 442-454 (2019). 
10. Jouny, M., Luc, W. \& Jiao, F. General techno-economic analysis of CO2 electrolysis systems. Ind. Eng. Chem. Res. 57, 2165-2177 (2018).

11. Bediako, D. K., Surendranath, Y. \& Nocera, D. G. Mechanistic studies of the oxygen evolution reaction mediated by a nickel-borate thin film electrocatalyst. J. Am. Chem. Soc. 135, 3662-3674 (2013).

12. Masa, J. et al. Amorphous cobalt boride (Co2B) as a highly efficient nonprecious catalyst for electrochemical water splitting: oxygen and hydrogen evolution. Adv. Energy Mater. 6, 1502313 (2016).

13. Nsanzimana, J. M. V. et al. Ultrathin amorphous iron-nickel boride nanosheets for highly efficient electrocatalytic oxygen production. Chem. Eur. J. 24, 18502-18511 (2018).

14. Su, L. et al. Borate-ion intercalated NiFe layered double hydroxide to simultaneously boost mass transport and charge transfer for catalysis of water oxidation. J. Colloid Interface Sci. 528, 36-44 (2018).

15. Gupta, S., Patel, M. K., Miotello, A. \& Patel, N. Metal boride-based catalysts for electrochemical water-splitting: A review. Adv. Funct. Mater. 30, 1906481 (2020).

16. Mabayoje, O., Shoola, A., Wygant, B. R. \& Mullins, C. B. The role of anions in metal chalcogenide oxygen evolution catalysis: electrodeposited thin films of nickel sulfide as "pre-catalysts". ACS Energy Lett. 1, 195-201 (2016).

17. Nsanzimana, J. M. V. et al. Facile synthesis of amorphous ternary metal borides-reduced graphene oxide hybrid with superior oxygen evolution activity. ACS Appl. Mater. Interfaces 11, 846-855 (2019).

18. Xu, X., Song, F. \& Hu, X. A nickel iron diselenide-derived efficient oxygenevolution catalyst. Nat. Commun. 7, 1-7 (2016).

19. De Luna, P. et al. What would it take for renewably powered electrosynthesis to displace petrochemical processes? Science 364, 6438 (2019).

20. Bajdich, M., Garcia-Mota, M., Vojvodic, A., Norskov, J. K. \& Bell, A. T. Theoretical investigation of the activity of cobalt oxides for the electrochemical oxidation of water. J. Am. Chem. Soc. 135, 13521-13530 (2013).

21. Dickens, C. F., Kirk, C. \& Nørskov, J. K. Insights into the electrochemical oxygen evolution reaction with ab Initio calculations and microkinetic modeling: Beyond the limiting potential volcano. J. Phys. Chem. C. 123, 18960-18977 (2019).

22. Rossmeisl, J., Logadottir, A. \& Nørskov, J. K. Electrolysis of water on (oxidized) metal surfaces. Chem. Phys. 319, 178-184 (2005).

23. Koper, M. T. Analysis of electrocatalytic reaction schemes: distinction between rate-determining and potential-determining steps. J. Solid State Electrochem 17, 339-344 (2013).

24. Romain, S., Bozoglian, F., Sala, X. \& Llobet, A. Oxygen- oxygen bond formation by the Ru-Hbpp water oxidation catalyst occurs solely via an intramolecular reaction pathway. J. Am. Chem. Soc. 131, 2768-2769 (2009).

25. Govindarajan, N., García-Lastra, J. M., Meijer, E. J. \& Calle-Vallejo, F. Does the breaking of adsorption-energy scaling relations guarantee enhanced electrocatalysis? Curr. Opin. Electrochem 8, 110-117 (2018).

26. Exner, K. S. A universal descriptor for the screening of electrode materials for multiple-electron processes: beyond the thermodynamic overpotential. ACS Catal. 10, 12607-12617 (2020).

27. Exner, K. S. Why approximating electrocatalytic activity by a single freeenergy change is insufficient. Electrochim. Acta 375, 137975 (2021).

28. Masa, J. et al. Ultrathin high surface area nickel boride (NixB) nanosheets as highly efficient electrocatalyst for oxygen evolution. Adv. Energy Mater. 7, 1700381 (2017).

29. Görlin, M. et al. Oxygen evolution reaction dynamics, faradaic charge efficiency, and the active metal redox states of $\mathrm{Ni}-\mathrm{Fe}$ oxide water splitting electrocatalysts. J. Am. Chem. Soc. 138, 5603-5614 (2016).

30. Wang, H. Y. et al. Ni3+-inducedformation of active $\mathrm{NiOOH}$ on the spinel $\mathrm{Ni}-\mathrm{Co}$ oxide surface for efficient oxygen evolution reaction. Adv. Energy Mater. 5, 1500091 (2015).

31. Hung, S.-F. et al. In situ spatially coherent identification of phosphide-based catalysts: crystallographic latching for highly efficient overall water electrolysis. ACS Energy Lett. 4, 2813-2820 (2019).

32. Weng, B. et al. A layered $\mathrm{Na} 1-\mathrm{xNiyFe} 1-\mathrm{yO} 2$ double oxide oxygen evolution reaction electrocatalyst for highly efficient water-splitting. Energy Environ. Sci. 10, 121-128 (2017).

33. Hong, W., Sun, S., Kong, Y., Hu, Y. \& Chen, G. NixFe1-xB nanoparticle selfmodified nanosheets as efficient bifunctional electrocatalysts for water splitting: experiments and theories. J. Mater. Chem. A 8, 7360-7367 (2020).

34. Wang, X. et al. Self-constructed multiple plasmonic hotspots on an individual fractal to amplify broadband hot electron generation. ACS Nano 15, 10553-10564 (2021)

35. Marshall, A. T. \& Vaisson-Béthune, L. Avoid the quasi-equilibrium assumption when evaluating the electrocatalytic oxygen evolution reaction mechanism by Tafel slope analysis. Electrochem. Commun. 61, 23-26 (2015).

36. Sun, S. et al. Switch of the rate-determining step of water oxidation by spinselected electron transfer in spinel oxides. Chem. Mater. 31, 8106-8111 (2019).
37. Li, H. et al. Amorphous nickel-cobalt complexes hybridized with 1T-phase molybdenum disulfide via hydrazine-induced phase transformation for water splitting. Nat. Commun. 8, 15377 (2017).

38. Kresse, G. \& Hafner, J. Ab initio molecular dynamics for liquid metals. Phys. Rev. B 47, 558 (1993).

39. Kresse, G. \& Furthmüller, J. Efficient iterative schemes for ab initio totalenergy calculations using a plane-wave basis set. Phys. Rev. B 54, 11169 (1996).

40. Perdew, J. P., Burke, K. \& Ernzerhof, M. Generalized gradient approximation made simple. Phys. Rev. Lett. 77, 3865 (1996).

41. Payne, M. C., Teter, M. P., Allan, D. C., Arias, T. \& Joannopoulos, A. J. Iterative minimization techniques for ab initio total-energy calculations: molecular dynamics and conjugate gradients. Rev. Mod. Phys. 64, 1045 (1992).

42. Larsen, A. H. et al. The atomic simulation environment-a Python library for working with atoms. J. Phys.: Condens. Matter 29, 273002 (2017).

43. Jain, A., Castelli, I. E., Hautier, G., Bailey, D. H. \& Jacobsen, K. W. Performance of genetic algorithms in search for water splitting perovskites. J. Mater. Sci. 48, 6519-6534 (2013).

44. Chase, M. W. NIST-JANAF thermochemical tables for oxygen fluorides. J. Phys. Chem. Ref. Data. 25, 551-603 (1996).

45. Rossmeisl, J., Qu, Z.-W., Zhu, H., Kroes, G.-J. \& Nørskov, J. K. Electrolysis of water on oxide surfaces. J. Electroanal. Chem. 607, 83-89 (2007).

46. Nørskov, J. K. et al. Origin of the overpotential for oxygen reduction at a fuelcell cathode. J. Phys. Chem. B 108, 17886-17892 (2004).

47. Cai, W. et al. Amorphous versus crystalline in water oxidation catalysis: A case study of NiFe alloy. Nano Lett. 20, 4278-4285 (2020).

48. Zou, Y. et al. 3D hierarchical heterostructure assembled by NiFe $\mathrm{LDH} /(\mathrm{NiFe})$ $\mathrm{Sx}$ on biomass-derived hollow carbon microtubes as bifunctional electrocatalysts for overall water splitting. Electrochim. Acta 348, 136339 (2020).

49. Chen, G. et al. An amorphous nickel-iron-based electrocatalyst with unusual local structures for ultrafast oxygen evolution reaction. Adv. Mater. 31, 1900883 (2019).

50. Zhou, Y. et al. Exceptional performance of hierarchical Ni-Fe (hydr) oxide@NiCu electrocatalysts for water splitting. Adv. Mater. 31, 1806769 (2019).

51. Teng, X. et al. Self-Growing NiFe-Based hybrid nanosheet arrays on $\mathrm{Ni}$ nanowires for overall water aplitting. ACS Appl. Energy Mater. 2, 5465-5471 (2019).

52. Qiu, Z., Tai, C.-W., Niklasson, G. A. \& Edvinsson, T. Direct observation of active catalyst surface phases and the effect of dynamic self-optimization in NiFe-layered double hydroxides for alkaline water splitting. Energy Environ. Sci. 12, 572-581 (2019).

53. Zhang, P. et al. Dendritic core-shell nickel-iron-copper metal/metal oxide electrode for efficient electrocatalytic water oxidation. Nat. Commun. 9, 1-10 (2018). 381.

54. Zhang, J. et al. Single-atom $\mathrm{Au} / \mathrm{NiFe}$ layered double hydroxide electrocatalyst: probing the origin of activity for oxygen evolution reaction. J. Am. Chem. Soc. 140, 3876-3879 (2018).

55. Dong, C., Kou, T., Gao, H., Peng, Z. \& Zhang, Z. Eutectic-Derived mesoporous Ni-Fe-O nanowire network catalyzing oxygen evolution and overall water splitting. Adv. Energy Mater. 8, 1701347 (2018).

56. Zhang, H. et al. Bifunctional heterostructure assembly of NiFe LDH nanosheets on NiCoP nanowires for highly efficient and stable overall water splitting. Adv. Funct. Mater. 28, 1706847 (2018).

57. Cai, Z. et al. Introducing $\mathrm{Fe}(2+)$ into Nickel-Iron layered double hydroxide: local structure modulated water oxidation activity. Angew. Chem. 57, 9392-9396 (2018)

58. He, T. et al. Synthesis of amorphous boride nanosheets by the chemical reduction of Prussian blue analogs for efficient water electrolysis. J. Mater. Chem. A 6, 23289-23294 (2018).

\section{Acknowledgements}

The N.W. and H.Y.L. acknowledge support from the National Natural Science Foundation of China (NSFC No. 51771132). The authors acknowledge funding from Canada's Natural Gas Innovation Fund, the Natural Sciences and Engineering Research Council (NSERC) of Canada, the Natural Resources Canada Clean Growth Program, and the Ontario Research Fund-Research Excellence program. All DFT computations were performed on the Niagara supercomputer of the SciNet HPC Consortium. SciNet is funded by the Canada Foundation for Innovation, the Government of Ontario, Ontario Research Fund Research Excellence Program, and the University of Toronto. The authors thank C.-L. Dong and Y.-R. Lu for technical support at the $20 \mathrm{~A}$ beamline in NSRRC. The authors acknowledge Taiwan Light Source (TLS) beamline 17C1, $20 \mathrm{~A} 1$ and Taiwan Photon Source (TPS) beamline 44A1 of NSRRC for providing synchrotron beamtime.

\section{Author contributions}

H.Y.L. and E.H.S. supervised the project. N.W. conceived the idea and carried out the experiments. N.W., H.Y.L., and E.H.S. wrote the paper. A.X. P.O., and Z.W. carried out 
the DFT computations. Y.X. and J.A. performed the in-situ XAS measurements. M.H. and K.Y. assisted in electrochemical experiments. Z.W. A.S. A.V., and S-F.H. polished the paper. A.O. integrated the OER catalyst into the CORR MEA electrolyser and tested the $\mathrm{C}_{2} \mathrm{H}_{4}$ production performance. S-F.H., A.O., and Z.W. assisted in data analysis and manuscript writing. All authors discussed the results and assisted during manuscript preparation.

\section{Competing interests}

The authors declare no competing interests.

\section{Additional information}

Supplementary information The online version contains supplementary material available at https://doi.org/10.1038/s41467-021-26307-7.

Correspondence and requests for materials should be addressed to Yongchang Liu, Edward H. Sargent or Hongyan Liang.

Peer review information Nature Communications thanks Abdoulaye Djire, Kai Exner, Justus Masa, and the other, anonymous, reviewers for their contributions to the peer review of this work.
Reprints and permission information is available at http://www.nature.com/reprints

Publisher's note Springer Nature remains neutral with regard to jurisdictional claims in published maps and institutional affiliations.

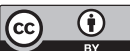

Open Access This article is licensed under a Creative Commons Attribution 4.0 International License, which permits use, sharing, adaptation, distribution and reproduction in any medium or format, as long as you give appropriate credit to the original author(s) and the source, provide a link to the Creative Commons license, and indicate if changes were made. The images or other third party material in this article are included in the article's Creative Commons license, unless indicated otherwise in a credit line to the material. If material is not included in the article's Creative Commons license and your intended use is not permitted by statutory regulation or exceeds the permitted use, you will need to obtain permission directly from the copyright holder. To view a copy of this license, visit http://creativecommons.org/ licenses/by/4.0/.

(C) The Author(s) 2021 